\title{
SISTEM KONTROL PINTU AIR OTOMATIS BERDASARKAN CURAH HUJAN MENGGUNAKAN SMS GATEWAY
}

\author{
Paundra A ${ }^{1}$, Akuwan Saleh ${ }^{2}$, Hani'ah $\mathbf{M}^{2}$, Ari W ${ }^{2}$ \\ ${ }^{1,2}$ Politeknik Elektronika Negeri Surabaya \\ Institut Teknologi Sepuluh Nopember ,Kampus ITS, Surabaya 60111 \\ Email : paundra.angga@yahoo.com
}

\begin{abstract}
Abstrak
Membuka dan menutup pintu air pada sungai atau bendungan berdasarkan ketinggian air di Indonesia masih dilakukkan secara manual menggunakan tenaga manusia sebagai penjaga pintu air. Hal ini sangat tidak efisien, sehingga pada penelitian ini dibuat suatu sistem kontrol otomatis buka dan tutup pintu air berdasarkan level curah hujan menggunakan mikrokontroller AVR ATmega8535 dan SMS.

Prinsip kerja dari sistem ini adalah HP pengirim (Tx) mendapat data dari database yang diolah dan diproses oleh perangkat lunak yaitu Visual Basic 6.0 dari PC server. Kemudian HP pengirim mengirim SMS ke HP penerima $(R x)$ kemudian pesan diteruskan ke Mikrokontroller. Mikrokontroller ini akan mengolah karakter pesan tersebut ke format PDU (Protocol Data Unit) dan bilangan hexadecimal sehingga dapat memberikan aksi yang berupa instruksi untuk menggerakkan driver motor yang telah terhubung dengan motor stepper yang secara otomatis membuka dan menutup pintu air dengan cara bergeser ke atas dan ke bawah sesuai level curah hujan.

Sistem pengiriman dan penerimaan sms kondisinya baik karena waktu delay sms-nya kurang dari 10 detik. Untuk kondisi yang paling baik saat mengirim dan menerima data berupa sms adalah pada siang hari, karena rata-ratanya $\pm 5,6$ detik, sedangkan untuk kondisi yang kurang baik yaitu pada malam hari, karena rata-ratanya $\pm 7,8$ detik.
\end{abstract}

Kata Kunci-Pintu air, Curah hujan, SMS

\section{PENDAHULUAN}

Mayoritas pintu air pada sungai besar ataupun bendungan di Indonesia untuk memonitor level air dan mengontrol tuas pembuka dan penutup pintu air tersebut masih bekerja secara manual [1]. Dalam membuka dan menutup pintu air, dibutuhkan tenaga manusia sehingga dalam sehari terdapat 3-4 penjaga pintu air yang harus siap siaga di dekat tuas pembuka dan penutup pintu air. Cara manual mempunyai faktor kekurangan yaitu, apabila para penjaga pintu tersebut lalai dalam tugasnya, maka tuas pembuka dan penutup pintu tidak berfungsi dengan baik sehingga dapat menyebabkan air meluber kemana-kemana.

Untuk mengatasi hal tersebut maka dibuat sebuah sistem kontrol otomatis pintu air sungai atau bendungan berdasarkan curah hujan agar dapat mengurangi tenaga manusia untuk menjaga pintu air tesebut. Sistem ini digunakan untuk mengontrol (buka dan tutup) pintu air dengan mengoptimalkan SMS pada handphone dan mikrokontroller [2][3]. Dengan adanya aplikasi SMS pada handphone dan mikrokontroller pada sistem ini diharapkan system lebih efisien dalam penggunaanya

\section{METODOLOGI}

\subsection{Perencanaan Sistem}

Untuk perencannaan sistem seperti pada Gambar 1. Penggunaan mikrokontroler tersebut berdasarkan I/O yang diperlukan oleh sistem. I/O yang diperlukan pada perencanaan sistem ini adalah serial interface yang terhubung ke HP penerima dan 4 bit output ke driver motor. Sehingga dalam sistem ini, mikrokontroler yang digunakan adalah mikrokontroler AVR ATMEGA8535.

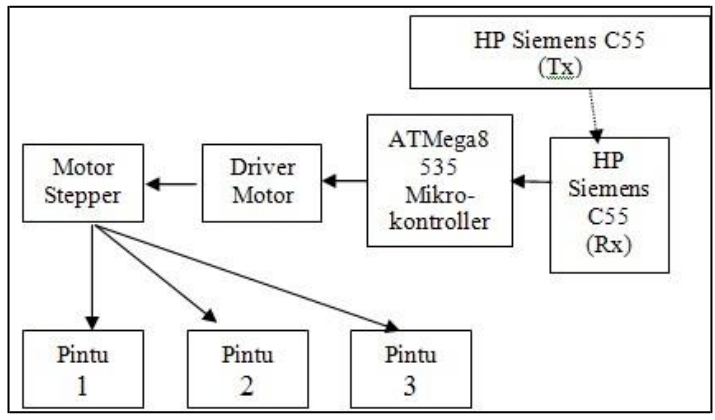

Gambar 1. Blok diagram sistem

Pada transmitter terdapat HP pengirim yang mengirimkan data dari database yang terkandung didalam perangkat lunak Visual Basic 6.0 berdasarkan level debit air yang 
terdiri dari rata-rata level curah hujan kemudian diproses pada PC Server.

Dengan teknologi SMS [6], data pada HP transmitter dikirimkan ke HP receiver yang terhubung dengan mikrokontroller ATmega8535 melalui komunikasi serial $R S$ -

232 kemudian diproses untuk mengaktifkan dan men-non aktifkan driver motor yang berfungsi untuk menggerakkan motor Stepper dengan membuka dan menutup pintu air tersebut berdasarkan level curah hujan rendah, sedang, dan tinggi. Untuk level rendah maka pintu pertama yang di buka, level sedang maka pintu kedua terbuka, dan level tinggi maka pintu ketiga yang terbuka.

Sedangkan untuk menutup ketiga pintu tersebut, mikrokontroller juga membaca tingkat level curah hujan, dimana untuk pintu ketiga menutup apabila level curah hujan berkurang melewati level hujan tinggi dan di antara level tinggi dan sedang. Untuk pintu kedua dan ketiga menutup, apabila level curah hujan telah berada di antara level sedang dan rendah. Dan untuk pintu pertama sampai pintu ketiga menutup dengan sempurna, apabila level curah hujan telah mencapai di bawah level curah hujan yang paling rendah dan sampai tidak ada kemungkinan terjadinya banjir. Untuk blok diagram sistem seperti pada Gambar 2.

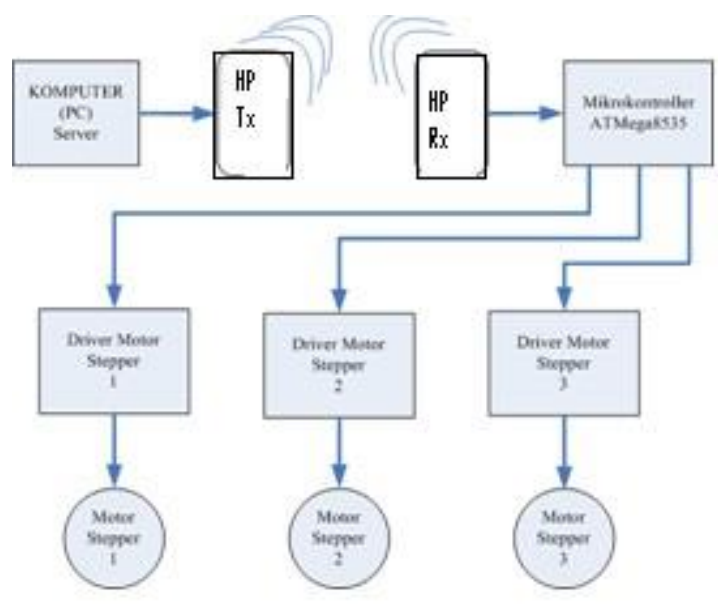

Gambar 2. Blok diagram sistem

Pada blok digram sistem terdiri dari blok diagram transmitter dan receiver.

Untuk bagian transmitter terdiri dari:

1. Personal Computer (PC) yang terdiri database level debit air yang terdiri dari rata-rata level curah hujan kemudian diproses pada PC Server. Proses masukkan data yang akan dikirimkan menggunakan form pada Visual Basic 6 .

2. Data level debit air yang dikirimkan via kabel data serial handphone berupa SMS (short Message Service) dikirimkan pada HP transmitter ke HP receiver. Setiap karakter data yang dikirimkan dari format PDU ke Teks [4][5][6][7].

Sedangkan untuk sistem receiver adalah sebagai berikut:

1. Data level debit air berupa sms yang dikirimkan oleh HP pengirim diterima oleh HP penerima.

2. Kemudian data yang diterima, diproses oleh mikrokontroller ATmega8535.

3. Dari hasil proses data yang diterima, didapat 3 operasi file kondisi intuk membuka pintu air yaitu kondisi 1 untuk mengoperasikan pintu 1 dengan perantara driver motor 1, kondisi 2 untuk mengoperasikan pintu 2 dengan perantara driver motor 2, kondisi 3 untuk mengoperasikan pintu 3 dengan perantara driver motor 3 .

\section{PEMBUATAN DAN ANALISA SISTEM}

Untuk pengiriman data berupa SMS, dilakukan secara otomatis menggunakan perangkat lunak Visual Basic 6.0 yang sudah dilengkapi dengan database kemudian melalui beberapa proses perhitungan menggunakan rumus level debit air yaitu $Q=C . I . A .0,278$, [7] dengan keterangan nilai I adalah intensitas hujan( $\mathrm{mm} / \mathrm{jam})$, nilai $\mathrm{C}$ adalah koefisien debit air sebesar 0.1 , dan nilai $A$ adalah luas daerah aliran sungai $\left(\mathrm{m}^{2}\right)$ yang diletakkan dalam form dan tabel datagrid seperti Gambar 3.

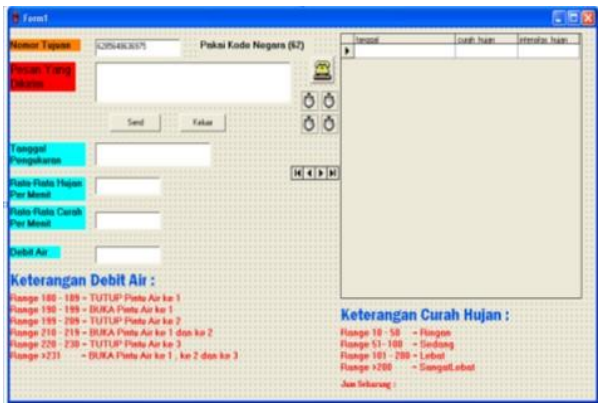

Gambar 3. Form Visual Basic Untuk Proses Pengiriman SMS dan Record Data

Untuk pembuatan minimum sistem AVR ATMega8535. Mikrokontroller ini terdiri rangkaian elektronika merupakan pusat untuk melakukan semua proses yang diperlukan minimum sistem AVR ATMega8535. Minimum sistem AVR ATMega8535 meliputi serial, Input/output, dan juga timer/counter terhubung dengan motor stepper. 
Motor Stepper adalah motor DC yang gerakannya bertahap (step per step) dan memiliki akurasi yang tinggi tergantung pada spesifikasinya. Setiap motor stepper mampu berputar untuk setiap stepnya dalam satuan sudut $\left(45^{\circ}, 90^{\circ}, 180^{\circ}\right)$. Untuk mengontrol gerakan motor stepper untuk berputar searah dengan jarum jam atau berlawanan arah dengan jarum jam dengan cara memberi logika 1 secara bergantian pada tiap-tiap pin mikrokontroler yang disetting sebagai output.

Berikut ini adalah tabel logika untuk menggerakkan motor stepper mode full step seperti Tabel 1.

Tabel 1. Tabel logika untuk menggerakkan motor stepper.

\begin{tabular}{|l|l|l|l|l|}
\hline Step & S3 & S2 & S1 & S0 \\
\hline 1 & 0 & 0 & 0 & 1 \\
\hline 2 & 0 & 0 & 1 & 0 \\
\hline 3 & 0 & 1 & 0 & 0 \\
\hline 4 & 1 & 0 & 0 & 0 \\
\hline 1 & 0 & 0 & 0 & 1 \\
\hline
\end{tabular}

Untuk pengaman menghindari adanya arus dari driver motor stepper masuk ke rangkaian minimum sistem menggunakan optoisolator. Rangkaian optoisolator menggunakan TLP521 merupakan komponen elektronic yang pada dasarnya terdiri dari 2 bagian yaitu LED dan phototransistor. Bila LED on maka menyebabkan phototransistor cut off.

Driver motor stepper terhubung pada masing-masing pintu air yang diletakkan tepat diatas pintu air tersebut dengan tujuan untuk mempermudah putaran motor stepper dalam proses membuka dan menutup pintu air. Untuk miniatur pembuatan mekanik miniatur pintu air dan rangakaian pengendali serta sensor seperti pada Gambar 4. dan 5.

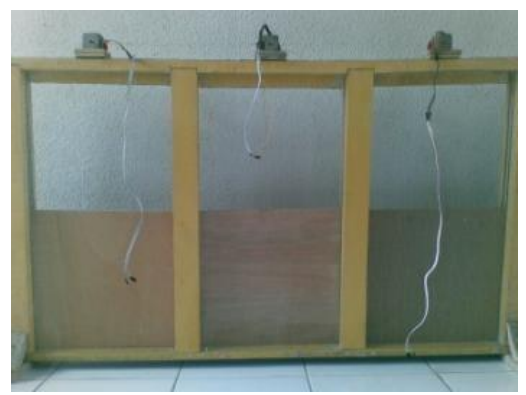

Gambar 4. Mekanik Miniatur Pintu Air

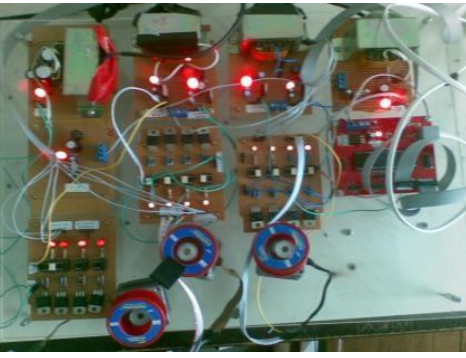

Gambar 5. Rangkaian keseluruhan dari pengendali driver motor dan motor stepper.

Untuk server database curah hujan dan database debit air menggunakan form visual basic yang sudah dijalankan akan muncul masing-masing nilai pada textbox yang dibuat sesuai dengan rencana dan script dari VB dan keterangan batas dari nilai level debit air dan level curah hujan. Apabila data yang masuk dan diproses dalam database sesuai dengan nilai batas keterangan debit air, maka sms yang dikirim juga sesuai dengan karakter pada keterangan debit air seperti pada Gambar 6.

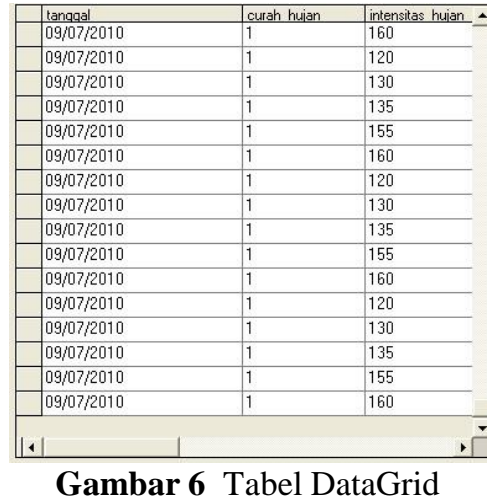

Pada Gambar 7., form visual basic yang sudah dijalankan akan muncul masing-masing nilai pada textbox yang dibuat sesuai dengan rencana dan script dari VB dan keterangan batas dari nilai level debit air dan level curah hujan. Apabila data yang masuk dan diproses dalam database sesuai dengan nilai batas keterangan debit air, maka sms yang dikirim juga sesuai dengan karakter pada keterangan debit air.

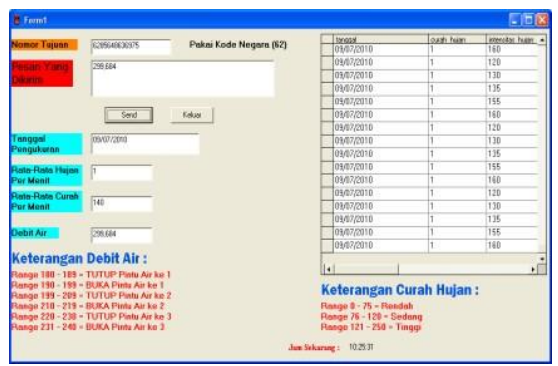

Gambar 7. Form proses pengiriman SMS dan record data yang sudah dieksekusi.

Pada Tabel 2 merupakan hasil pengambilan dan pengujian alat yang dilakukan pada 3 kondisi yaitu pagi hari, siang hari, dan malam hari. Untuk pengambilan data di waktu traffic sistem komunikasinya padat. 
Tabel 2. Hasil pengambilan data ratarata dalam satuan detik.

\begin{tabular}{|c|c|c|c|c|}
\hline Kondisi & $\begin{array}{c}\text { Waktu } \\
\text { Pengiri- } \\
\text { man }\end{array}$ & $\begin{array}{c}\text { Waktu } \\
\text { Peneri- } \\
\text { maan }\end{array}$ & $\begin{array}{l}\text { Delay } \\
\text { (detik) }\end{array}$ & $\begin{array}{c}\text { Rata- } \\
\text { rata } \\
\text { (detik) }\end{array}$ \\
\hline \multirow{5}{*}{ Pagi Hari } & $07: 12: 52$ & $07: 12: 58$ & 6 & \multirow{5}{*}{5,8} \\
\hline & $07: 15: 13$ & $07: 15: 18$ & 5 & \\
\hline & $07: 20: 33$ & $07: 12: 40$ & 7 & \\
\hline & $07: 21: 22$ & $07: 20: 27$ & 5 & \\
\hline & $07: 22: 00$ & $07: 22: 06$ & 6 & \\
\hline \multirow{5}{*}{ Siang Hari } & $12: 36: 47$ & $12: 36: 53$ & 6 & \multirow{5}{*}{5,6} \\
\hline & $12: 37: 30$ & $12: 37: 35$ & 5 & \\
\hline & $12: 38: 01$ & $12: 38: 07$ & 6 & \\
\hline & $12: 38: 20$ & $12: 38: 07$ & 4 & \\
\hline & $12: 39: 05$ & $12: 39: 12$ & 7 & \\
\hline \multirow{5}{*}{$\begin{array}{c}\text { Malam } \\
\text { Hari }\end{array}$} & $23: 05: 16$ & $23: 05: 24$ & 8 & \multirow{5}{*}{7,8} \\
\hline & $23: 05: 48$ & $23: 05: 57$ & 9 & \\
\hline & $23: 06: 28$ & $23: 06: 37$ & 9 & \\
\hline & $23: 07: 01$ & $23: 07: 08$ & 7 & \\
\hline & $23: 07: 31$ & $23: 07: 37$ & 6 & \\
\hline
\end{tabular}

Sistem pengiriman dan penerimaan sms kondisinya baik karena waktu delay sms-nya kurang dari 10 detik. Untuk kondisi yang paling baik saat mengirim dan menerima data berupa sms adalah pada siang hari, karena rata-ratanya $\pm 5,6$ detik, sedangkan untuk kondisi yang kurang baik yaitu pada malam hari, karena rata-ratanya $\pm 7,8$ detik.

\section{KESIMPULAN}

Pada penelitian ini dapat diambil kesimpulan bahwa sistem untuk mengontrol pintu air secara otomatis diperlukan sebuah ponsel user, sebuah ponsel server, Interface CodeVision AVR dan peralatan yang dikontrol yaitu motor stepper. Untuk semua pengujian sistem pada kondisi baik pagi, siang, maupun malam, sistem pengiriman dan penerimaan sms kondisinya baik karena waktu delay sms-nya kurang dari 10 detik. Untuk kondisi yang paling baik saat mengirim dan menerima data berupa sms adalah pada siang hari, karena rata- ratanya $\pm 5,6$ detik, sedangkan untuk kondisi yang kurang baik yaitu pada malam hari, karena rata- ratanya $\pm 7,8$ detik.

\section{DAFTAR PUSTAKA}

[1] Kepmen Pemukiman Dan Prasaran Wilayah, "Perencanaan Bendungan Karet Isi Udara", Oktober 2004.

[2] Praja, Aditya, B, "Rancang Bangun Sistem Pembuka Menggunakan Sensor Infrared dan Password Berbasis Mikrokontroller", PENS-ITS,Surabaya,2006

[3] Iman, Ma'rifatul, "Rancang Bangun Sistem Otomatis Pintu Garasi Berbasis Mikrokontroller dan SMS”, PENS-ITS, Surabaya, 2003
[4] Manual Book Reference AT Command, 2010

[5] www.gsmfavorites.com/documents/sms/pdutext, "Pengaturan Konversi PDU Untuk Mikrokontroller”, 2010.

[6] I Nyoman Putra Sastra, "Perancangan dan Pembuatan Sistem kontrol Dengan memanfaatkan Layanan SMS Telepon seluler Berbasis Mikrokontroler", E-Journal Teknik Elektro Vol. 4 No. 2 Juli - Desember 2005

[7] Referensi level debit air, “Berita Utama „Detik Bandung" Data Level Debit Air Di Daerah Rawan Banjir," 2010. 